\title{
VARIAÇÃO LINGUÍSTICA E ENSINO: O CASO DO SUBSISTEMA VOCÁLICO PRETÔNICO ${ }^{1}$
}

\section{LINGUISTIC VARIATION AND TEACHING: THE CASE OF VOCALIC PRE- STRESSED SUBSYSTEM}

José Sueli Magalhães²

RESUMO: Embora amplamente discutido por inúmeros pesquisadores, 0 ensino de língua ainda continua tradicionalmente pautado pela prescrição gramatical, postulando o que se pode e o que não se pode, o que é certo e o que é errado. Objetivamos, pois, neste artigo trazer à tona mais uma discussão sobre como transformar este cenário prescritivo em um ambiente de ensino/aprendizagem no qual a variação linguística possa contribuir para 0 ensino efetivo que considere não apenas uma, mas várias modalidades de linguagem (ou uso dela). Para tanto, focalizaremos alguns trabalhos que tratam do estudo das vogais do português brasileiro - essencialmente o subsistema pretônico - em suas diversas manifestações, a partir de dados coletados junto a informantes do "dialeto" do Triângulo Mineiro. Esta proposta visa a contribuir não apenas com a formação plural do professor, como também a discutir a relevância de uma prática educativa que considere, de fato, a variabilidade linguística como o ponto de partida para a formação de qualidade que se deseja ao educando.

Palavras chave: VARIAÇÃO LINGUÍSTICA, VOGAIS PRETÔNICAS, ENSINO PRODUTIVO

ABSTRACT: Although widely discussed by many researchers, language teaching is still guided by traditional grammar prescription, that postulate what is allowed and disallowed, what is right and wrong. The aim of this paper is to bring up another discussion about how to change this prescriptive scenario to an environment of teaching/learning in which language variation may contribute to effective teaching that considers not only one but several types of language (or the use of them). In order to achieve this goal we will focus our attention on some works dealing with the study of vowels in Brazilian Portuguese essentially the pre-stressed subsystem - in its various manifestations. We will use data collected from informants who speech the "dialect" of Triângulo Mineiro. This proposal aims to contribute not only with the plural formation of the teacher, but also to discuss the relevance of an educational practice that consider, in fact, the linguistic variability as the starting point for a complete formation of the students.

1 Trabalho apresentado no III SELL - SIMPÓSIO INTERNACIONAL DE ESTUDOS LINGUISTICOS E LITERÁRIOS, no período de 11 a 13 de maio de 2011, Mesa redonda "VARIAÇÃO LINGUISTICA E ENSINO".

${ }^{2}$ Professor Doutor da Universidade Federal de Uberlândia (UFU). E-mail: $\underline{\text { mgsjose@gmail.com }}$ 
Keywords: LINGUISTIC VARIATION, PRE-STRESSED VOWELS, PRODUCTIVE TEACHING

\section{Introdução}

Embora amplamente questionado por inúmeros pesquisadores nos últimos anos, especialmente a partir da década de 80 do século passado, o ensino de língua ainda continua tradicionalmente pautado pela prescrição gramatical, postulando o que se pode e o que não se pode, o que é certo e o que é errado. Algumas alternativas contra a priorização do ensino prescritivo foram bem delineadas com o advento e maciça aceitação das chamadas gramáticas de texto, que partiam não mais da palavra ou da frase, mas do texto como o elemento gerador do trabalho a ser realizado, buscando focar em características da textualidade para desenvolver não somente as habilidades de leitura, mas também de interpretação e produção de novos textos. Contudo, conforme assevera Guy e Zilles (2006), em se tratanto verdadeiramente do ensino de língua, é necessário considerar que "a criança já chega à escola sabendo sua língua; sendo assim, pergunta-se: o que cabe à escola ensinar? Não há dúvida de que a resposta, em se considerando que a língua não existe em si mesma, mas em seu uso, o que envolve o falante, o contexto de fala, o ouvinte, o ambiente, entre outros aspectos, é que a escola deve prover o aluno do instrumental necessário para se manifestar nas mais diferentes possibilidades que a língua the oferece.

Apesar de inúmeras críticas, a escola ainda costuma pautar o ensino de língua em atividades artificiais, herméticas e voltadas para uma prática que não considera a pluralidade linguística e ainda trata uma norma eleita como padrão como a única merecedora de créditos em sala de aula. Esquece-se de que, se nem mesmo um único indivíduo fala do mesmo jeito sempre, o que esperar de comunidades formadas por indivíduos diferentes, de origens diversas, comportamentos, experiências e vivências também diferentes?

Focando-se exclusivamente nas práticas de sala de aula, retomamos aqui algumas ponderações de Guy e Zilles (2006) que apontam três direções que a escola tem seguido referentemente ao ensino de língua, a saber: 
a- Alfabetização: caracteriza-se por representações escritas - relações arbitrárias, porém necessárias. Esta uniformiza, por meio de um código, um tratado que deve ser obedecido por todos os usuários da língua. Neste momento, em que todas as atenções estão voltadas para a grafia, o objetivo é fazer com que os múltiplos falares, ou a variação possível na fala, tornem-se convergentes em um único código - documental e inevitável - que é a escrita.

b- Literatura e estética: identificada por objetos linguísticos valorizados pela sociedade, ou considerados artísticos e significativos. Para os autores, este não é o ensino de língua propriamente dito, é o ensino de uma variedade fruto de produtos culturais valorizados e prestigiados. Mesmo que, para o aluno, estes objetos não tenham o valor ou o prestígio que Ihes foram atribuídos, é papel da escola fazer com que os discentes os reconheçam com este mesmo prestígio; Travaglia (2003) chama a atenção para este aspecto. Para o autor, o ensino de língua portuguesa, ainda tradicional, vem amparado nos renomados autores de textos literários. Contudo, muitas vezes, o efeito vem na direção contrária do pretendido, isto é, o aluno passa a distanciar-se dos textos artísticos e, por vezes, a antipatizar-se com eles.

a- Ensino normativo: está é a variedade de ensino promovida por forças e relações de poder. Neste caso, é como o ensino de língua estrangeira, em que se considera que o aluno entra não sabendo as peculiaridades estruturais ou léxicas da variedade padrão. É como se estivesse ensinando um novo dialeto, ou um novo idioma, para quem não conhece o dialeto padrão ao chegar à escola. Qualquer aspecto que destoe desta variedade é um desvio, erro, falha, burrice, etc. Aqui, a principal característica é o ensino de regras gramaticais (concordância, regência), nomenclatura e classificação de fatos linguísticos: memorização! Por fim, "a ideologia do certo é contrariada maciçamente pela experiência da criança". 
Acrescentamos que nesta vertente de ensino normativo uma prática pungente é aquela puramente pautada na metalinguagem em que definições, não necessariamente centradas em objetivos bem definidos, pautam as atividades de sala de aula com tarefas meramente estruturais que, muitas vezes, seguem um modelo artificial e de ilusória aplicação prática. Tudo isso ainda nos moldes bloomfiedianos ou comportamentalistas em que conceitos são incansavelmente repetidos, sem que professor e, principalmente, o aluno compreenda o porquê do empreendimento nessa tarefa.

Passada décadas desde o advento da Sociolinguística (LABOV, 1972), e mesmo após inúmeras pesquisas considerando que fatores não apenas linguísticos, mas também externos, como a cultura, a etnia, a classe social, o sexo, etc, estão diretamente ligados à manifestação da língua, ainda é incipiente o avanço relativamente à aplicação dessas descobertas ao ensino. Destacando-se a importância da descrição linguística e a valorização das variedades de fala, fica ainda no patamar quase insignificante a aplicação desses achados à prática pedagógica, esta ainda cerceada pela normatização prescritiva. Mencionamos, contudo os esforços de pesquisadores como Bagno, Bortoni-Ricardo, Molica e, mais recentemente, Coan e Freitag (2011), entre outros.

Nossa avaliação a esse respeito justifica-se por percebermos que inúmeros trabalhos questionam de forma veemente a prática ditadora da norma padrão nas escolas e salientam a necessidade de pluralizar ou dialetalizar as atividades de ensino de língua; todavia a associação desses questionamentos à prática ainda são tímidos.

Por vezes, ao se propor uma abordagem de ensino baseada nas descobertas das pesquisas sociolinguísticas em que se considera a estrutura social da linguagem, os dialetos, a diversidade linguística, variação e mudança, o contato linguístico, adaptação do falante ao ouvinte, muitas barreiras são interpostas, dada a dificuldade de se romper com o poderio da norma padrão que ainda dita o que está certo e o que está errado, o que é permitido e o que é proibido. Contudo, é de se considerar que um uso linguístico somente é efetivamente inaceitável quando uma pessoa se afasta tanto da linguagem de 
sua comunidade que não é mais compreendida; nesse sentido, sim, pode-se dizer que a prática da comunidade falante impõe limites para garantirmos 0 entendimento dos nossos enunciados, única situação em que somos obrigados a nos conformar às estruturas sintáticas e às pronúncias que nosso interlocutor conhece (Guy e Zilles 2006).

Buscando trazer os achados da sociolinguística variacionista - tratando de um fenômeno fonológico específico - para a prática pedagógica efetiva, Gonçalves (1997) postula que a contribuição de forma decisiva para o ensino de língua vernácula deveria seguir em duas direções, fundamentalmente: (a) a formação do professor, no sentido de fazer com que ele assuma uma visão mais aberta e menos preconceituosa quanto às potencialidades do sistema; e (b) a confecção de material didático, em especial o reconhecimento de que determinados fatores atuam de forma mais decisiva que outros na escolha de uma ou de outra alternativa estrutural de dizer a mesma coisa (ou variante) que o sistema oferece. Concordamos com Gonçalves e tantos outros estudiosos a este respeito, contudo, cremos na necessidade urgente de levar ao professor 0 entendimento desses fatos para que se conscientize de que os fenômenos variáveis são latentes, estão à sua volta e em si próprio como falante da língua que ensina. Cremos, também, que é preciso levar ao conhecimento professor os resultados de pesquisas com dados de variação para que ele entenda que tais resultados nada mais são do que análises da fala de cidadãos como ele, como seus alunos, seus familiares, enfim: falantes!

A partir dessas considerações, pretendemos, na sequência deste trabalho, trazer à tona o caso das vogais pretônicas do Português Brasileiro, sistema caracterizado por intensa variação em todos os dialetos já pesquisados por inúmeros autores, a fim de que sejam propostas não apenas algumas reflexões, mas também o entrelaçamento dos estudos de variação com uma prática pedagógica democrática, reflexiva e linguisticamente respeitadora, de modo a tornar o ensino uma atividade efetivamente produtiva.

\section{0 sistema vocálico do Português Brasileiro}


Estudos pioneiros acerca da descrição do sistema vocálico do Português Brasileiro são devidos a Camara Jr. (1953, 1970), com base na fonêmica estruturalista. $O$ autor delimita um quadro de 7 vogais distintivas na sílaba tônica, o qual vai, derivacionalmente, reduzindo-se em sistemas menores, à medida que as vogais se posicionem em sílaba pretônica, átona não final e átona final.

Parece não haver discordância do fato de que, na posição tônica, o Português Brasileiro comporta um sistema de 7 vogais, conforme abaixo:

(1) Sistema de vogais na posição tônica:

Altas

Médias

Médias

grau)

Baixa /i/

/e/

/E/

la/

frontais central posteriores

Baseado no conceito estruturalista de Neutralização, de Trubetzkoy, Câmara Jr. documenta o desaparecimento da oposição entres as vogais médias de $1^{\circ}$ e $2^{\circ}$ graus na posição pretônica. Na posição postônica não-final (em proparoxítonas), o autor admite a neutralização entre $/ 0 /$ e $/ \mathrm{u} /$, mas não entre /e/ e /i/ como na pronúncia num[i]ro para "número". Na posição átona final, seguida ou não de /s/, há a neutralização de /e/ - /i/ e de /o/ - /u/. Portanto, três quadros de vogais átonas surgem:

(2) $1^{\circ}$ quadro: vogais pretônicas
Altas
/i/
Médias
lê/
/ô/
Baixa
la/

/u/

(3) $2^{\circ}$ quadro: vogais postônicas não finais 


$\begin{array}{lllll}\text { Altas } & \text { /i/l } & & & \text { /u/ } \\ \text { Médias } & & \text { lêl/ } & \ldots \\ \text { Baixa } & & \text { /a/ } & \end{array}$

(4) 3ำ quadro: vogais átonas não finais
Altas
/u/
/i/
Baixa
la/

A oposição entre /o/ e /u/ na posição pretônica fica comprometida devido à harmonização vocálica, já que a vogal alta da sílaba tônica promove, normalmente, a elevação das vogais médias das sílabas antecedentes, como em "comprido" (longo) versus "cumprido" (executado). Situação semelhante ocorre com /o/ e /e/ nos hiatos: "passear" > "passiar", "voar"> "vuar".

Esses postulados de Câmara Jr tem servido como ponto de partida para análises variacionistas. As hipóteses do autor a partir do dialeto do Rio de Janeiro, advindas da experiência de um exímio linguista observador, serão depois confirmadas ou refutadas pelos estudos variacionistas. Nosso intento com esta retomada, contudo, foi o de apenas rever os quadros descritivos das vogais do Português Brasileiro. Passemos, pois, ao objetivo primeiro deste trabalho.

\section{Variação das vogais médias pretônicas - pensando no ensino}

De todas as posições silábicas possíveis para as vogais do PB, certamente a posição em sílaba pretônica é a mais variável. E de todas as vogais, as médias são aquelas que mais são alvejadas por fenômenos fonológicos. Iniciado em 2005, o PROBRAVO, projeto para Estudo das Vogais do Português Brasileiro, que reúne pesquisadores de todas as regiões do Brasil, tem atribuído especial atenção a esse subsistema por sabê-lo portador 
de características que o diferenciam, por exemplo, do bem descrito subsistema átono final, constituído de três vogais com poucas variações que, se ocorrem, são, nos mais das vezes, regionais e localizadas em pontos da fronteira sul do país.

Mas o que dizer das vogais pretônicas? Inicialmente, é necessário considerar que a posição pretônica é múltipla, pois antes da sílaba tônica pode haver muitas outras sílabas. Assim, pode haver sílaba pretônica adjacente à tônica, ou distante uma, duas, três ou até mais posições com relação à sílaba mais forte na palavra, conforme atestam os exemplos a seguir:

a- Sílaba pretônica adjacente à sílaba tônica me.nino co.rrida for.miga Re.cife co.ruja fe.rrugem

b- Sílaba pretônica distante uma posição com relação à sílaba tônica for.mi.guinha fo.ru.jão en.fe.rru.jado pequenino

c- Sílaba pretônica distante duas ou mais posições com relação à sílaba tônica

pe.ri.fe.ria

re.be.li.ão

es.te.ti.cista

es.ta.ba.bi.li.za.dor 
Além do aspecto distância da sílaba tônica, as vogais médias pretônicas podem variar dependendo de inúmeros outros fatores, tais como:

a- qualidade da sílaba em que se encontra (pesada ou leve);
co.rrida for.miga
pe.rigo pes.quisa
de.lito des.file

b- posição da sílaba com relação à borda esquerda da palavra (inicial ou não)
fe.liz
in.fe.liz
co.lorido
co.lo.rido
so.lúvel
ab.so.luto

c- processo do qual a vogal pretônica é alvo (alçamento, abaixamento)

$$
\begin{aligned}
& \text { formiga }>\text { furmiga goiaba }>\text { gOiaba } \\
& \text { moleque }>\text { muleque colégio }>\text { cOlégio } \\
& \text { perigo }>\text { perigo meleca }>\text { mEleca } \\
& \text { menino }>\text { minino meleca }>\text { mEleca }
\end{aligned}
$$

Esses são apenas exemplos de elementos linguísticos que estão circunscritos na variação das vogais médias pretônicas. Além de outros fatores internos ao sistema, há vários fatores extralinguísticos que podem promover esta ou aquela realização da vogal, tais como a faixa etária do falante, os anos de escolarização, o grupo social a que pertence o indivíduo etc.

Como nossa proposta inicial é tratar da variação das vogais pretônicas no dialeto do Triângulo Mineiro, retomo aqui alguns dados que demonstram com este fenômeno ocorre nesta região, recorrendo ao corpus do GEFONO (Grupo de Estudos em Fonologia, da Universidade Federal de Uberlândia).

Traremos dados de falantes das cidades de Monte Carmelo (Rezende e Magalhães, 2010) e de Ituiutaba (Bisinotto, 2011). 


\section{4- O alçamento vocálico}

Bisinotto (2011), em seu trabalho com informantes de Ituiutaba e valendo-se no pacote de programas para análise estatística GOLDVARB, detectou que as vogais médias pretônicas são comumente alçadas e o fator que mais favorece o alçamento é a presença de uma vogal alta na sílaba tônica, com peso relativo de .85, comparativamente a outras vogais. Vejamos a tabela a seguir:

\begin{tabular}{l|l|l|l}
\hline $\begin{array}{l}\text { Vogal } \\
\text { da } \\
\text { sílaba } \\
\text { tônica }\end{array}$ & $\begin{array}{l}\text { Número de } \\
\text { ocorrênicas } \\
\text { com } \\
\text { alçamento }\end{array}$ & $\begin{array}{l}\text { Porcentagem } \\
\%\end{array}$ & $\begin{array}{l}\text { Peso } \\
\text { relativo }\end{array}$ \\
\hline $\begin{array}{l}\text { Vogal } \\
\text { alta }\end{array}$ & $145 / 250$ & 37 & .85 \\
\hline $\begin{array}{l}\text { Vogal } \\
\text { média } \\
\text { alta }\end{array}$ & $17 / 505$ & 3 & .25 \\
\hline Nasal & $51 / 440$ & 11,5 & \\
\hline Vogal & & & .52 \\
baixa & $5 / 174$ & 3 & .22 \\
\hline
\end{tabular}

Fonte: Bisinotto, 2011

Exemplos:

Vogal alta tônica: sintido, sirviço, siguro, perigo, minino, iscola, ixame, filipe, quirido

Embora a presença de vogal alta na sílaba tônica favoreça o alçamento da vogal média pretônica, há casos de alçamento pretônico mesmo havendo alguma vogal não alta como, por exemplo, em muleque, piqueno, bulacha, pumada, etc. (outros trabalhos também detectaram este fenômeno com dados 
de outras regiões do país: Bisol 1981; Viegas 1987, Viana 2008, Silveira 2008, Pereira 2010, entre outros)

A análise desta tabela e a focalização nos exemplos faz surgir um primeiro questionamento:

- Como explicar em sala de aula, especialmente para alunos em alfabetização, que palavras como "ispeto, sintido, sirviço, minino, iscola, inxame", embora assim pronunciadas são escritas com a letra "e"?

O primeiro ato desta peça exige que o professor tenha consciência de que a realização na fala desta vogal alçada é variável e, como tal, poderá ser pronunciada como "e" ou como "i".

Voltaremos a esta questão mais adiante. Passemos a outro fenômeno envolvendo as vogais médias pretônicas:

\section{5- 0 abaixamento vocálico}

Nos dados do GEFONO, outro aspecto do Português Falado no Triângulo Mineiro é a variação entre vogais médias altas e médias baixas, isto é, casos em que as vogais médias pretônicas alternam de /e/ e /o/ a [E] e [O]. No quadro abaixo, separamos os dados de menor ocorrência à esquerda e os de maior ocorrência à direita, considerando essas variantes:

\begin{tabular}{|l|l|}
\hline \multicolumn{1}{|c|}{ Menos ocorrência } & \multicolumn{1}{c|}{ Mais ocorrência } \\
\hline relógio & rElógio \\
\hline geleia & gEleia \\
\hline meleca & mEleca \\
\hline perereca & pErEreca \\
\hline rebeca & rEbeca \\
\hline pEdágio & pedágio \\
\hline colégio & cOlégio \\
\hline pOrrada & porrada \\
\hline IOtada & lotada \\
\hline pOmada & pomada cf. pumada \\
\hline tOmate & tomate cf. tumate \\
\hline
\end{tabular}


O que dizer desses dados?

Embora ainda não tenhamos feito uma análise estatística de todos os dados envolvendo o abaixamento das vogais médias pretônicas, dúvida semelhante à recém-exposta surge: como explicar ao educando que palavras que se escrevem sempre com as letras "e" e "o" são pronunciadas como [e] ou [E] e [o] ou [O] respectivamente? Especialmente nos últimos exemplos, como explicar ao aluno os fatos abaixo:

- "tumate": o aluno certamente pronuncia; (cf. "pumada")

- "tomate": o aluno certamente pronuncia; (cf. "tumate")

- "pOmada": aluno certamente não pronuncia, mas não estranharia; (cf. "tOmate")

Porém,

- "tomada": o aluno certamente pronuncia;

- "tOmada": o aluno certamente não pronuncia, mas não estranharia;

- "tumada": o aluno certamente não pronuncia e estranharia.

Lemle (2000) chama a atenção para casos em que uma só letra aparece representando mais de um som e em que mais uma letra representa um único som. Para as consoantes, o primeiro caso pode ser exemplificado com a letra "s", que representa os sons /s/ (suco), /z/ (casa); exemplos do segundo caso estão em [s] que pode ser representado pelas letras "s" (suco), "c" (cedo), "xc" (exceto), "x" (máximo), etc.

Todavia, no caso variável das vogais médias pretônicas, consideramos esta relação ainda mais complexa, pois os exemplos de Lemle não se referem a dados de variação.

Conforme, apontamos acima, o advento da sociolinguística e, por consequência, dos estudos variacionistas, revelam que a língua não é um todo uniforme. Ao contrário, a língua é caracterizada por intensa variabilidade que envolve não apenas fatores linguísticos, mas também elementos externos de natureza social, cultural, econômica, etc. Ignorar essa verdade em sala de aula significa trabalhar para que se perpetue o autoritarismo linguístico que 
escolheu uma norma dita padrão em detrimento de inúmeras outras modalidades, incluindo aquela que o aluno já domina bem.

Entendemos, assim, que os estudos variacionistas têm muito a colaborar para tornar o ensino mais real e próximo do que vivencia o aluno, possibilitando que ele conheça não apenas a norma padrão mas também outras variedades, de modo a ser instrumentalizado a participar ativamente de diferentes contextos sociais, utilizando, no momento adequado, a modalidade de fala também adequada.

Trazendo à tona estudos variáveis das vogais médias pretônicas, voltemos, pois, a primeira pergunta acima:

- Como explicar em sala de aula, especialmente para alunos em alfabetização, que palavras como "ispeto, sintido, sirviço, minino, iscola, inxame", embora assim pronunciadas, são escritas com a letra "e"?

Conhecendo os dados de variação fonológica, uma nova pergunta surge: existem de fato palavras como "estrela", "espeto", "enxame", pronunciadas com "e"? Não apenas os dados do Triângulo Mineiro, como também trabalhos com informantes de outras regiões do país (cf. Bisol 1981 com dados do Sul) revelam que a presença de [e] antes de [s] e [N] tem-se tornado cada vez mais rara, de modo que o alçamento da vogal média para [i], nessa situação, pode ser considerado categórico.

O que dizer então ao aluno? Ou, antes, conhece o professor esses fenômenos? O falante aprendeu "estrela" e diz "istrela", "espeto" e diz "ispeto", "enxame" e diz "inxame" e terá que aprender a escrever com "e", ou ele já aprendeu "istrela, ispeto e inxame" e terá que treinar a escrever com "e". Ouvirá o aluno que ele aprendeu "errado" e que o certo é "estrela, espeto, enxame"? Certamente, ele ouvirá que aprendeu errado, caso o professor não tenha conhecimento dos fatos de variação fonológica. Dirá o professor que este é mais um caso em que o aluno deverá escrever diferente da forma como fala, sem necessariamente refletir sobre o sistema variável em que os indivíduos estão inseridos. Ora, especificamente nesses casos, tudo indica que esta é uma das situações que Labov (2007) chama de "transmissão linguística", ou seja, a criança já aprende dessa forma. 
Retomemos, agora, a segunda questão: como explicar ao educando que uma palavra que se escreve sempre com a letra "e" é pronunciada com timbres diferentes, como em "geleia" e gEleia"? Ou como explicar ao aluno que a pronúncia "pumada", que ele certamente fala, juntamente com "pomada", e sem estranhar "pOmada", embora não pronuncie esta última, não corresponde ao caso de "tomada" que ele certamente fala, e sem estranhar "tOmada", mas tendo como inexistente a pronúncia "tumada"?

Tratemos, inicialmente, da ocorrência das vogais médias coronais "geleia" e "gEleia".

Temos aqui duas realizações altamente variáveis, embora a segunda opção seja preferida no Triângulo Mineiro. O que dizer ao educando? Primeiramente, algo tem que ser dito ao professor: formas como esta coocorrem e são perfeitamente condizentes com a realidade do aluno, seja na pretensão de atingir um nível culto de linguagem seja respeitando outras modalidades. Menos problemática, não há outra letra, se não a letra "e" para representar qualquer uma das formas. Mas e casos como "pomada" e "pumada", predominantes na fala do Triângulo Mineiro e "pOmoada", mais rara, em oposição a "tomada", predominante, "tOmada, forma menos comum e "tumada", realização extremamente rara? E mais, como lidar com essa situação que, na modalidade escrita, só admite a letra "o"?

Da mesma forma referida anteriormente, é necessário que, primeiro, o professor conheça os fatos variáveis da língua, a fim de que se aposse do conhecimento necessário para não agir intempestivamente e, baseado no autoritarismo, aponte alguma variante como errada.

\section{Considerações finais}

Todos os dados e reflexões aqui apresentados convergem para uma única direção, qual seja: antes de qualquer atitude a ser tomada, cumpre que professor percorra algumas etapas a saber:

1- tenha plena consciência de que a língua não tem um perfil uniforme e de que esta não uniformidade é latente na fala, em suas mais variadas formas de manifestação; 
2- tome conhecimento, a partir do que vai ensinar, dos fenômenos variáveis em que se circunscreve aquilo que pretende levar ao aluno. Não estamos, com isso, recomendando que o professor realize inúmeras pesquisas em variação linguística. Já há muitas feitas e estas podem servir como elementos basilares ao educador;

3- entenda que, mesmo em sua sala de aula, a língua pode não estar se manifestando uniformemente, pois entre seus alunos deve haver perfis socioculturais, econômicos e étnicos diferentes, o que, segundo Labov (1972), e conforme verificado em vários estudos, favorece a variação;

4- conheça e aceite a língua que seus alunos falam, pois, antes de buscar, elementos fora da sala de aula para fundamentar suas atividades, as variáveis linguísticas que interessam podem estar diante de seus próprios olhos.

Para finalizar, manifestamos o reconhecimento ao trabalho que muitos pesquisadores tem feito para tentar levar a pesquisa sociolinguística até o interior da sala de aula, mesmo que os obstáculos de uma histórica tradição formal, árida e hermética ainda insistam em dificultar uma prática de ensino voltada verdadeiramente para a concepção democrática e de respeito às inúmeras formas possíveis de manifestação linguística.

\section{Referências Bibliográficas}

BAGNO, Marcos. Não é errado falar assim. São Paulo: Parábola, 2009.

BISINOTTO, A. G. O alçamento das vogais médias pretônicas: um estudo do falar ituiutabano. Dissertação (Mestrado). Programa de pós-graduação em estudos linguísticos, UFU, Uberlândia, 2011.

BISOL, L. Harmonia vocálica: uma regra variável. 1981. 352 f. Tese (Doutorado em Linguística) - Departamento de Linguística e Filologia, Universidade Federal do Rio de Janeiro, Rio de Janeiro, 1981. 
BISOL, L.; MAGALHÃES, J. S. de. "A redução vocálica no Português Brasileiro: avaliação via restrições". In Revista da Abralin, vol III, nos. 1 e 2, p. 195216, julho e dezembro, 2004.

BORTONI-RICARDO, Stella Maris. Educação em língua materna: a sociolinguística na sala de aula. São Paulo: Parábola, 2004.

CALLOU, D.; MORAES, J. A.; LEITE, Y. "O vocalismo no Português do Brasil". In Letras de Hoje, v. 31, no 2, p. 27-40, Porto Alegre, junho, 1996.

CÂMARA JR., J. M. Estrutura da Língua Portuguesa. Petrópolis: Vozes, 1970.

CÂMARA JR., J. M. Para o estudo da Fonêmica Portuguesa. Petrópolis: Vozes, 1953.

COAN, M. e FREITAG, R. M. K. "Sociolinguística variacionista: pressupostos teórico-metodológicos e propostas de ensino." In. Domínios da Lingu@gem. Vol 4, no. 2, UFU, Uberlândia, 2010.

GONÇALVES, C. A. V. "Ditongos descrescente: variação \& ensino". In. Rev. Est. Ling. ano 6. no. 5 vol. 1, p. 159-192, UFMG, Belo Horizonte, 1997.

GUY, G. R. e ZILLE, A.M.S. "O ensino da língua materna: uma proposta sociolinguística". In: Calidoscópio, vol. 4. No. 1. Pa. 39-50, Unisinos, São Leopoldo, 2006.

LABOV, W. Padrões Sociolinguisticos. Tradução de Marcos Bagno, Maria Marta Pereira Scherre, Caroline Rodrigues Cardoso. São Paulo: Parábola,[1972] 2008. 392 p. Tradução de Sociolinguistic Patterns.

LEMLE, M. Guia Teórico do Alfaberizador. Ática, São Paulo, 2000.

MAGALHÃES, J. S. de. "A redução vocálica no Português Brasileiro por diferentes modelos fonológicos". In. Hora, D. O. (org.) Vogais no ponto mais oriental das Américas. Ideia, João Pessoa, 2009.

MAGALHÃES, J. S. de. "A redução vocálica no plano métrico do Português Brasileiro". In: In Focus: Léxico e Morfofonologia: Perspectivas e Análises vol. 4, p. 325 - 336. Uberlândia: EDUFU, 2006.

MOLLICA, M. C.; BRAGA, M. L. (orgs.) Introdução a Sociolingüística: o tratamento da variação. São Paulo: Contexto, 2007. p. 135-145 
REZENDE, F. A. e MAGALHÃES, J. S. de. "Alçamento da vogal pretônica /e/ na fala dos habitantes de Coromandel e Monte Carmelo-MG. In Linguagem: Estudos e Pesquisas, vol. 14, no. 2, p. 58-78, Catalão, UFG, julhodezembro, 2010

TRAVAGLIA, Luiz Carlos. Gramática e interação: uma proposta para o ensino de gramática. São Paulo: Cortez, 2003.

VIANA, V F. As vogais médias pretônicas em Pará de Minas: um caso de variação lingüística. 2008. 143f. Dissertação (Mestrado em Linguística) Programa de Pós-Graduação em Letras, Pontifícia Universidade Católica de Minas Gerais, Belo Horizonte, 2008.

VIEGAS, M. do C. O alçamento de vogais médias pretônicas: uma abordagem sociolinguística. 1987. 222 f. Dissertação (Mestrado em Linguística) - Faculdade de Letras da UFMG, Universidade Federal Minas Gerais, Belo Horizonte, 1987.

0 alçamento de vogais médias pretônicas e os itens lexicais. 2001. 256 f. Tese (Doutorado em Letras) - Faculdade de Letras da UFMG, Universidade Federal Minas Gerais, Belo Horizonte, 2001 